\title{
A comparison of two methodologies for the selection of foods in a total diet study
}

\author{
N. F. C. Devlin ${ }^{1}$, B. A. McNulty ${ }^{1}$, A. Turrini ${ }^{2}$, C. Tlustos ${ }^{3}$, A. P. Hearty ${ }^{1}$, J. L. Volatier ${ }^{4}$, \\ C. C. Kelleher ${ }^{1}$ and A. P. Nugent ${ }^{1}$ \\ ${ }^{1}$ UCD Institute of Food and Health, University College Dublin, Ireland, ${ }^{2}$ INRAN, National Research Institute on Food \\ and Nutrition, Italy, ${ }^{3}$ Food Safety Authority of Ireland and ${ }^{4}$ ANSES, France
}

Total diet studies (TDS) assess exposure to chemical substances in food, thereby facilitating risk assessments and health monitoring ${ }^{(1)}$. Candidate foods for inclusion in a TDS list should represent a large part of a typical diet to accurately estimate exposure of the population and/or specific population groups. There are currently no harmonised TDS guidelines for the selection of foods, with varying methodologies used worldwide ${ }^{(2)}$. The aim of this study was to compare the influence of two approaches in compiling a TDS food list using data from the adult cohort of the EFSA Comprehensive Database ${ }^{(3)}$. This database was developed from national food consumption surveys across Europe. Potential TDS foods were selected if they satisfied the criteria of either comprising $90 \%$ of the weight of each food group (method 1) or comprising $90 \%$ of the weight of the total diet plus $\geqslant 5 \%$ consumer rate (method 2). The number of selected TDS foods and their percentage $(\%)$ contributions to the diet are presented for Ireland and France.

\begin{tabular}{|c|c|c|c|c|c|c|c|c|}
\hline \multirow[b]{3}{*}{ Food Groups } & \multicolumn{4}{|c|}{ Ireland } & \multicolumn{4}{|c|}{ France } \\
\hline & \multicolumn{2}{|c|}{$\begin{array}{c}\text { Method } 1 \\
\end{array}$} & \multicolumn{2}{|c|}{$\begin{array}{l}\text { Method } 2 \\
\end{array}$} & \multicolumn{2}{|c|}{ Method 1} & \multicolumn{2}{|c|}{ Method 2} \\
\hline & $\%$ Contr & $n$ & $\%$ Contr & $n$ & $\%$ Contr & $n$ & $\%$ Contr & $n$ \\
\hline Grains and grain products & 6.6 & 16 & 5.3 & 6 & 7.9 & 21 & 7.1 & 13 \\
\hline Vegetable \& vegetable products & 4.7 & 15 & 3.4 & 5 & 5.2 & 23 & 4.2 & 13 \\
\hline Starchy roots and tubers & 7.7 & 2 & 8.1 & 3 & 2.4 & 3 & 2.5 & 4 \\
\hline Legumes, nuts and oilseeds & 0.5 & 3 & 0.4 & 1 & 1.3 & 5 & 1.2 & 4 \\
\hline Fruits and fruit products & 2.8 & 12 & 2.0 & 3 & 5.0 & 15 & 4.7 & 12 \\
\hline Meat and meat products & 5.2 & 7 & 5.2 & 7 & 4.9 & 16 & 4.2 & 9 \\
\hline Fish and other seafood & 0.7 & 6 & 0.2 & 1 & 1.2 & 15 & 0.5 & 2 \\
\hline Milk and dairy products & 9.2 & 4 & 9.2 & 4 & 7.4 & 18 & 6.2 & 9 \\
\hline Eggs and egg products & 0.4 & 1 & 0.4 & 1 & 0.6 & 1 & 0.6 & 1 \\
\hline Sugar and confectionary & 0.9 & 7 & 0.7 & 2 & 1.0 & 9 & 0.6 & 2 \\
\hline Fats \& oils & 1.1 & 4 & 0.9 & 2 & 0.9 & 5 & 0.6 & 2 \\
\hline Fruit and vegetable juices & 1.0 & 3 & 0.9 & 1 & 1.9 & 5 & 1.9 & 5 \\
\hline Non-alcoholic beverages & 26.8 & 5 & 29.1 & 9 & 16.7 & 7 & 18.2 & 11 \\
\hline Alcoholic beverages & 11.8 & 3 & 12.2 & 4 & 4.3 & 8 & 4.3 & 8 \\
\hline Drinking water & 10.7 & 1 & 10.7 & 1 & 30.5 & 2 & 32.2 & 3 \\
\hline Herbs, spices and condiments & 0.6 & 11 & 0.3 & 1 & 0.8 & 14 & 0.2 & 1 \\
\hline Snacks, desserts \& other foods & 0.4 & 4 & 0.2 & 1 & 0.8 & 5 & 0.5 & 2 \\
\hline Other & 0.9 & 11 & 0.5 & 2 & - & - & - & 0 \\
\hline Contribution of TDS foods to the diet & 92.0 & 115 & 89.7 & 54 & 92.9 & 174 & 89.7 & 101 \\
\hline
\end{tabular}

\%Contr: percentage contribution of TDS foods to dietary intake; $n$ : number of TDS foods.

Using 'method 1' the \% contribution of TDS foods to the total diet is 92.0 and $92.9 \%$, representing 115 and 174 TDS foods for Ireland and France, respectively. For method 2, a \% contribution of $89.7 \%$ for both Ireland and France represent 54 and 101 foods, respectively. Although additional 'risk' foods (shellfish etc.) should be added to the list depending on the contaminant of interest, this research shows that reasonably small TDS food lists may strongly represent the overall diet. In terms of budget planning and analytical capacity, these methods may provide cost-saving tools in deriving a TDS food list. Future consortium work will define a food shopping plan and ensure all chemicals of interest are accounted for.

The research leading to these results received funding from the European Union 7th Framework Programme (FP7/2007-2013) under Grant Agreement 289108 (Total Diet Study Exposure). This publication reflects only the authors' views, and the Community is not liable for any use made of the information contained therein.

1. EFSA, FAO and WHO (2011) EFSA Journal 9(11), 2450

2. EFSA, FAO and WHO (2011) Supporting publications 2011:206.

3. EFSA Comprehensive European Food Consumption Database (2011) European Food Safety Authority. 